\title{
Adrenarche in the rat
}

\author{
Duarte Pignatelli, Fang Xiao', Alexandra M Gouveia, Jorge G Ferreira and Gavin P Vinson ${ }^{1}$ \\ Laboratório de Biologia Celular e Molecular da Faculdade de Medicina da Universidade do Porto and IBMC, Alameda Hernani Monteiro, 4200-319 Porto, \\ Portugal \\ ${ }^{1}$ School of Biological and Chemical Sciences, University of London, Queen Mary, London E1 4NS, UK \\ (Requests for offprints should be addressed to D Pignatelli; Email: dpignatelli@yahoo.com)
}

\begin{abstract}
Normal pubertal development in humans involves two distinct processes: maturation of adrenal androgen secretion (adrenarche) and activation of the hypothalamic-pituitary-gonadal axis (gonadarche). One factor thought to contribute to the adrenarche in man is increased adrenal 17-hydroxylase (CYP17) activity. In the rat, there is evidence for adrenal involvement in the initiation of puberty, but the adrenal glands of this species are generally thought to express CYP17 only very poorly at best. To further examine the nature of postnatal adrenal development in rat, plasma samples and adrenal tissues were taken from animals aged 2-90 days, circulating adrenal
\end{abstract}

steroids assayed, and adrenal zones assessed quantitatively. A relative increase in zona reticularis, and peaks of circulating cortisol, androstenedione, and 17-OH-progesterone were observed around postnatal days 16-20, clearly before the development of the gonads, which begins at 30-35 days. Quantitative reverse transcriptase PCR confirmed a peak in mRNA coding for CYP17 in adrenal tissue from rats of similar age. The results suggest that the rat adrenal has the capacity to secrete steroids arising from 17-hydroxylation, and that this may contribute to a process similar to human adrenarche.

Journal of Endocrinology (2006) 191, 301-308

\section{Introduction}

In addition to glucocorticoids and aldosterone, the human adrenal gland secretes other steroids, which are either true androgens or serve as precursors for androgen formation in peripheral tissues. Preceding puberty in man, the adrenal gland secretes increasing amounts of androgens, particularly dehydroepiandrosterone and its sulfate (Rosenfield \& Eberlein 1969, Hopper \& Yen 1975, Lee \& Migeon 1975, Sizonenko \& Paunier 1975, de Peretti \& Forest 1976, Ducharme et al. 1976, Korth-Schutz et al. 1976, Reiter et al. 1977, Genazzani et al. 1978, Grumbach et al. 1978, Parker et al. 1978, Parker 1991, Parker \& Odell 1980, Pintor et al. 1980, Rich et al. 1981, Smail et al. 1982, Perez-Fernandez et al. 1987). At the same time, a new cortical zone develops, the zona reticularis, which is often held to be responsible for the secretion of such $\mathrm{C}_{19}$ steroids. The process is known as adrenarche (Albright et al. 1942, Dhom 1973, Parker \& Odell 1980, Parker 1991) and has been described only in humans and higher primates (Cutler et al. 1978, Winter et al. 1980, Smail et al. 1982). The hormonal control of adrenal androgen secretion is poorly understood and the mechanisms responsible for adrenarche have been the subject of considerable investigation.

The participation of the adrenal gland in the maturation of the hypothalamic-pituitary-gonadal axis (with the adrenal androgens contributing to the activation of this axis) has been suggested, particularly because of the clear temporal sequence between adrenarche and gonadarche (Boyar et al. 1973, Gorsky \& Lawton 1973, Forest et al. 1975, Sizonenko 1978a,b, Cutler \& Loriaux 1980, Ojeda et al. 1980, Smail et al. 1982, Katz et al. 1985, Parker 1991). This influence could be the result of one or a combination of the following mechanisms:

- direct action of the adrenal steroid hormones on the gonads;

- an action at the central nervous system (CNS), either facilitating the development of neuronal interconnections or inducing the secretion of gonadotropins or still, altering its pulsatile pattern;

- a permissive action (either at the gonads or at the CNS).

Alternatively, adrenarche may simply represent a progressive maturation in the activities of steroidogenic enzymes (such as 17,20 lyase) resulting from the increase in adrenal size, with no specific physiological significance.

In the rat, CYP17 has been generally considered to be absent from the adrenal cortex (Van Weerden et al. 1992, Pelletier et al. 2001) thus explaining why corticosterone, instead of cortisol, is the main glucocorticoid produced by the adrenal gland in this species. Nevertheless, several authors have reported the production of steroids arising from 17-hydroxylation (Bardin \& Peterson 1967, Askari 1970, Kniewald et al. 1971, Milewich \& Axelrod 1972, Vinson et al. 1976, 1978a,b, Bell et al. 1979), while other authors' findings are equivocal (Belanger et al. 1990, Leal \& Moreira 1997). 
However, the adrenals certainly influence the timing of puberty in the rat, and Corey \& Britton (1931) first showed that the implantation of adrenal extracts was able to initiate early puberty. Moon (1937) then reported that vaginal opening did not occur following adrenalectomy, but this could be reversed by the administration of adrenocorticotropin (ACTH). Later, Gorsky \& Lawton (1973) found that puberty is significantly delayed by adrenalectomy at 18 or 25 days postnatally, but not at 35 days. They also autotransplanted adrenal tissue into different groups of adrenalectomized rats and found that the pubertal delay was corrected when autotransplantation was performed at 18 days, but not at later times. They postulated that an adrenal factor was instrumental in the development of puberty, and since the adrenal autotransplants do not have a medulla, this factor must be of cortical origin.

Studies have also shown that male rat orchidectomy induces an increase in mitotic activity in the rat adrenal zona reticularis (Andò et al. 1989) and it also frequently causes the development of adrenal cortex tumors (Woolly et al. 1939, Houssay et al. 1953, Woolly 1953). Bell et al. (1978, 1979) demonstrated adrenal androstenedione production in vitro, although steroid secretion by zona reticularis cells was always inefficient when compared with the zona fasciculata. ACTH stimulation increases the output of steroids by both the two inner zones of the adrenal cortex. Supporting data were produced by Andò et al. (1988), who showed that castration in adult male rats induced the adrenal secretion of androstenedione and this tended to maintain the circulating levels of androgens. Finally, Rilianawati et al. $(1998,2000)$ using a transgenic mouse model for the study of gonadal tumorigenesis (inhibin $\alpha$-subunit promoter/SV-40 Tantigen) noted that gonadectomy induced the development of adrenal tumors and this phenomenon was gonadotropin-dependent. These facts implied the ectopic expression of luteinizing hormone (LH) receptors (together with increased levels of the ligand) in adrenal cortex tumorigenesis in these gonadectomized rodents, perhaps with the implication that the adrenal cortex can be stimulated to produce androgens.

The present studies were designed to examine the nature of adrenarche in the rat and test the possibility that changes in steroid output, including the secretion of androgens, might be involved.

\section{Materials and Methods}

Male and female Wistar rats were used. The animals were sacrificed at 2-day intervals between birth and postnatal day 20 and at 5-day intervals from day 20 until adulthood. The rats were kept under normal laboratory conditions with lights on from 0700 to $1900 \mathrm{~h}$ and a dark period from 1900 to $0700 \mathrm{~h}$. Room temperature was kept constant at $20^{\circ} \mathrm{C}$. The animals were allowed free access to food and water. After weaning, which took place at around postnatal days 17-18, they were placed in cages according to the date of birth and sex, with not more than three or four rats per cage. They were handled gently by the same operator to minimize stress.

The rats were killed by decapitation. This always took place between 0900 and $1100 \mathrm{~h}$ in order to avoid the effects of circadian variation. After death, truncal blood was collected, with and without EDTA, and after centrifugation, serum and plasma aliquots were kept at $-20^{\circ} \mathrm{C}$ (or $-70^{\circ} \mathrm{C}$, if the interval before assay was expected to be long) for the hormone assays. The adrenal glands were also rapidly dissected, weighed, and fixed. Both Bouin fluid and buffered formalin were used. After dehydration, the glands were embedded in paraffin and sections of $5 \mu \mathrm{m}$ were cut and stained with hematoxylin and eosin for light microscopy. Only equatorial sections were used (i.e. those with the largest diameter) and at least three sections per rat were examined. The cortex and the zones were drawn using a camera lucida and their areas determined with an image analyzer (MOP Videoplan, Kontron Elektronik, Munich, Germany). The testes of the male rats were also dissected and weighed in order to confirm puberty. A minimum of ten animals was used at each time point.

\section{Hormone assay}

Corticosterone was assayed by HPLC. All other hormones were determined by RIA using commercial RIA kits (cortisol, Amersham; androstenedione, Incstar, Stillwater, MN, USA; 17-OH-progesterone, and testosterone, DPC, Los Angeles, CA, USA). The detection limits, cross-reactivities, and coefficients of variation (CV) are presented in Table 1.

\section{Real-time reverse transcription and PCR (RT-PCR) and RT-PCR}

Adrenal RNA from adult male Wistar rats (60 days, 200-300 g), obtained from the colony of the Gulbenkian Institute of Science, Oeiras, Portugal, as well as developing male and female rats of the same species resulting from breeding in the Faculty of Medicine of Porto, Portugal, was prepared using RNeasy Mini Kit (Qiagen) according to the manufacturer's protocol and quantified spectrophotometrically by measuring absorbance at 260 and $280 \mathrm{~nm}$. The total RNA purity $\left(A_{260} / A_{280}\right)$ was between 1.6 and 1.9 . The quality of RNA was confirmed by ethidium bromide staining after $1 \%$ agarose gel fractionation. The extracted RNA was stored at $-70{ }^{\circ} \mathrm{C}$ until required.

\section{Primers}

For amplification of CYP17 and glyceraldehyde 3-phosphate dehydrogenase (GAPDH), primers were chosen from the previously published sequences (Horikoshi \& Sakakibara 2000, Thompson et al. 2005). The sequences of the sense and antisense primers for CYP17 were 5'-TGGCTTTCCTGGTGCACAATC- $3^{\prime}$ and $5^{\prime}$-TGAAAGTTGGTGTTCGGCTGAAG $-3^{\prime}$ respectively, corresponding to bases 973-993 and 1062-1040. For GAPDH, sense and antisense 
Table 1 Characterisation of radioimmunoassays

\begin{tabular}{|c|c|c|c|c|}
\hline & Detection limit & Cross reactivities & Intra-assay CV (\%) & Inter-assay CV (\%) \\
\hline Androstenedione & $0 \cdot 1 \mathrm{ng} / \mathrm{ml}$ & $\begin{array}{l}\text { Corticosterone }<0 \cdot 01 \% \\
\text { Cortisol } 0 \cdot 02 \%\end{array}$ & $6 \cdot 4$ & $11 \cdot 1$ \\
\hline Cortisol & $0 \cdot 1 \mu \mathrm{g} / \mathrm{dl}$ & $\begin{array}{l}\text { Cortisone } 0 \cdot 27 \% \\
\text { Corticosterone } 0 \cdot 34 \% \\
11 \text {-deoxycortisol } 3 \cdot 17 \% \\
17 \text {-OH-progesterone } 1 \cdot 91 \%\end{array}$ & $5 \cdot 7$ & $8 \cdot 9$ \\
\hline 17-OH-progesterone & $0.07 \mathrm{ng} / \mathrm{ml}$ & $\begin{array}{l}\text { Androstenedione } 0 \cdot 021 \% \\
\text { Testosterone } 0 \cdot 008 \% \\
\text { Cortisol } 0 \cdot 01 \% \\
\text { Progesterone } 3 \cdot 5 \% \\
\text { Corticosterone } 0 \cdot 000 \%\end{array}$ & $4 \cdot 0$ & $4 \cdot 8$ \\
\hline Testosterone & $0.04 \mathrm{ng} / \mathrm{ml}$ & $\begin{array}{l}\text { Androstenedione } 0 \cdot 5 \% \\
\text { Corticosterone } 0 \cdot 002 \% \\
\text { Cortisol } 0 \cdot 005 \%\end{array}$ & $5 \cdot 5$ & $10 \cdot 4$ \\
\hline
\end{tabular}

$\mathrm{CV}$, coefficient of variation.

primers were $5^{\prime}$-CCC TCA AGA TTG TCA GCA ATG C-3' and 5'-GTC CTC AGT GTA GCC CAG GAT-3' corresponding to bases $422-443$ and $831-811$ respectively.

\section{Quantitative RT-PCR (QRT-PCR)}

QRT-PCR was conducted, as previously described (Xiao et al. 2004), with minor modifications. Using Brilliant SYBR Green QRT-PCR Master Mix Kit, one-step, based on realtime detection of accumulated fluorescence (Mx300P; Stratagene, Amsterdam, The Netherlands), QRT-PCR was performed according to the manufacturer's protocol. Total cellular RNA, $200 \mathrm{ng}$, was used per reaction. QRT-PCR was carried out using the following time courses: $50{ }^{\circ} \mathrm{C}$ for $30 \mathrm{~min}$ (first-strand) cDNA synthesis, $95^{\circ} \mathrm{C}$ for $10 \mathrm{~min}$, and 45 cycles of $95^{\circ} \mathrm{C}$ for $30 \mathrm{~s}, 60^{\circ} \mathrm{C}$ for $1 \mathrm{~min}$, and $72{ }^{\circ} \mathrm{C}$ for $1 \mathrm{~min}$ for amplification. The amplified products were subjected to a stepwise increase in temperature from 55 to $95^{\circ} \mathrm{C}$ and dissociation curves were constructed. The relative amount of each mRNA was normalized to the housekeeping gene $(G A P D H)$ mRNA. Each sample was tested in triplicate.

\section{Conventional RT-PCR}

Reverse transcription was carried out at $23{ }^{\circ} \mathrm{C}$ for $20 \mathrm{~min}$ and at $42{ }^{\circ} \mathrm{C}$ for $60 \mathrm{~min}$ using $5 \mu \mathrm{g}$ RNA, $1 \mu \mathrm{l}$ reverse transcriptase (Moloney Murine Leukemia Virus Reverse Transcriptase, M-MLV RT, $200 \mathrm{U} / \mu \mathrm{l} ; \mathrm{Gibco})$ and $1 \mu \mathrm{l}$ random hexamers $(3 \mu \mathrm{g} / \mu \mathrm{l}$; Gibco) in a $20 \mu \mathrm{l}$ reaction mixture. Single-stranded cDNA $(1 \mu \mathrm{l})$ in the $20 \mu \mathrm{l}$ reaction mixture was amplified with $25 \mathrm{pmol}$ each of sense and antisense primers, and $0.5 \mu \mathrm{l}$ Taq DNA polymerase $(5 \mathrm{U} / \mu \mathrm{l})$ added to $50 \mu \mathrm{l} \mathrm{PCR}$ buffer $-20 \mathrm{mmol} / 1$ Tris $-\mathrm{HCl}(\mathrm{pH} 8 \cdot 4)$, $50 \mathrm{mmol} / 1 \mathrm{KCl}, 1.5 \mathrm{mmol} / 1 \mathrm{MgCl}_{2}, 0 \cdot 2 \mathrm{mmol} / 1$ each of dATP, dGTP, dCTP, and dTTP. The reactions were performed for $1 \mathrm{~min}$ at $94{ }^{\circ} \mathrm{C}, 1 \mathrm{~min}$ at $60{ }^{\circ} \mathrm{C}$ and $1 \mathrm{~min}$ at $72{ }^{\circ} \mathrm{C}$ for 40 cycles with a final extension of $5 \mathrm{~min}$ at $72{ }^{\circ} \mathrm{C}$. RT-PCR products were electrophoresed in $10 \mu \mathrm{l}$ aliquots on
$2 \cdot 5 \%$ agarose gel. RT-PCR products were purified using Wizard SV Gel and PCR Clean-Up System (Promega) and sequenced by Lark Technologies, Inc. (Essex, UK) and Qiagen GmbH (Hilden, Germany).

\section{Statistical analysis}

The significance of the differences found in the results was determined by ANOVA and the correlation between every parameter and postnatal age was studied by linear regression and significance determined by Student's $t$-test.

\section{Results}

The weights of the animals showed an almost linear growth until postnatal age of 70-75 days, in both males and females (correlation coefficients $>0.95$ ), and the same was true for adrenal weight. The area of the cortex (Fig. 1) and the areas of zonae fasciculata and reticularis (Figs 2 and 3) also increased from birth to adulthood with an attenuation of this growth after 60 days.

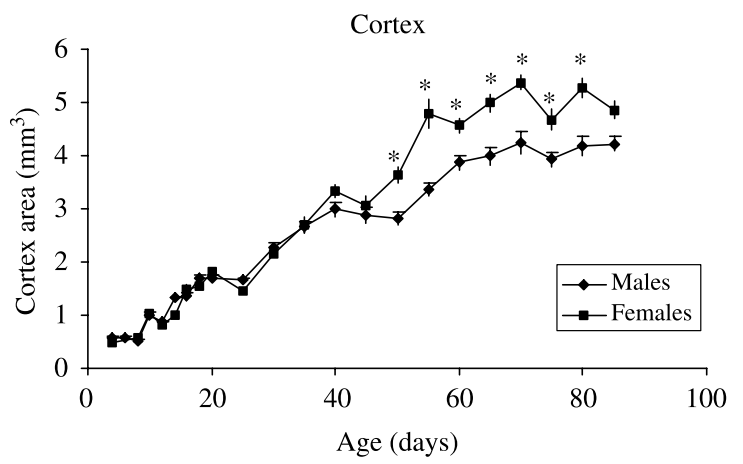

Figure 1 Development of the adrenal cortex in male and female rats during the postnatal period (mean \pm S.E.M., $n \geq 10$ throughout). $* P<0 \cdot 05$. 


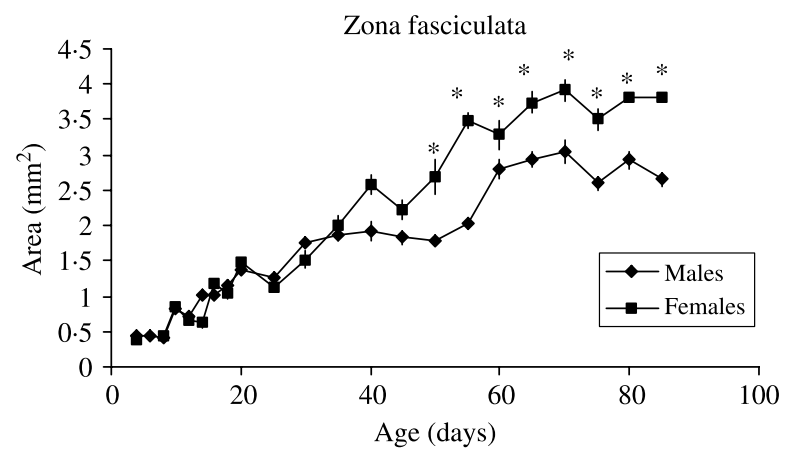

Figure 2 Development of the zona fasciculata in male and female rats during the postnatal period (mean \pm S.E.M., $n \geq 10$ throughout). $* P<0 \cdot 05$.

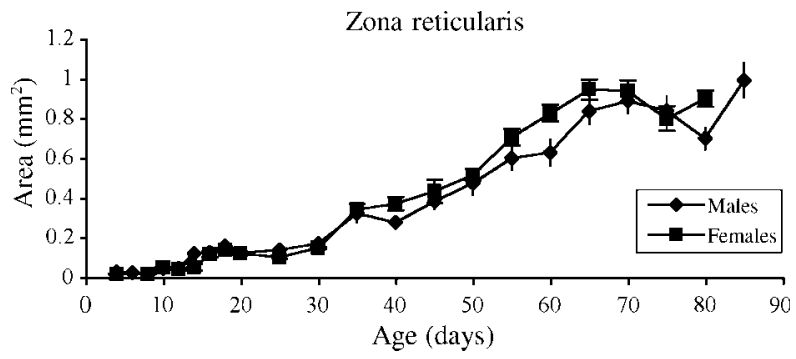

Figure 3 Development of the zona reticularis in male and female rats during the postnatal period (mean \pm S.E.M., $n \geq 10$ throughout).

The adrenal weight as well as the area of the cortex (Fig. 1) and zona fasciculata (Fig. 2), but not the area of the zona reticularis (Fig. 3), exhibited sexual divergence after puberty, being larger in female rats than in males.

Although cells that were apparently zona reticularis could be identified earlier (and data indicating this is included in the figures), the zona reticularis became established as a clearly identifiable zone only after postnatal day 10 . The ratio of the zona reticularis area to the cortical area (zona reticularis/cortex) increased with time implying that the proportion of the cortical area occupied by the zona reticularis increased from birth and more specifically from postnatal day 10 to adulthood (Fig. 4).

Corticosterone, which is the major glucocorticoid produced by the rat adrenal cortex, increased linearly from birth to adulthood (Fig. 5). After a brief period in which levels were close to the detection limits (coinciding with the stress hyporesponsive period), corticosterone levels augmented progressively until 40 days of age. From then on, values stabilized in the males, while in females corticosterone levels continued to increase, to become stable only around 60 days, contributing to the significant differences between adult males and females.

In contrast, cortisol, 17-OH-progesterone and androstenedione increased both in male and female rats, without sex differences, between postnatal days 16 and 20 (Figs 6-8). These secretory peaks were clearly identifiable at a period which preceded puberty, as was confirmed by plotting testicular weight or the testosterone levels against postnatal age both of which confirmed that puberty takes place later, from $30 / 35$ to $55 / 60$ days after birth (Figs 9 and 10).

After 25/30 days of age, the cortisol and androstenedione peaks returned to very low levels, close to the detection limits of the RIA kits that were employed (Figs 6 and 7). In contrast, circulating $17-\mathrm{OH}$-progesterone again became elevated to give a later peak only in the female, possibly reflecting the development of the ovary (Fig. 8).

\section{QRT-PCR}

PCR products derived from developing rat adrenals are illustrated in Fig. 11. They showed the presence of components of an appropriate size for CYP17 and identical with those obtained from ovary and testis. The sequence data were obtained from nucleotides 973-1062 (NM 012753.1, Genebank) and sequences were identical to that expected for

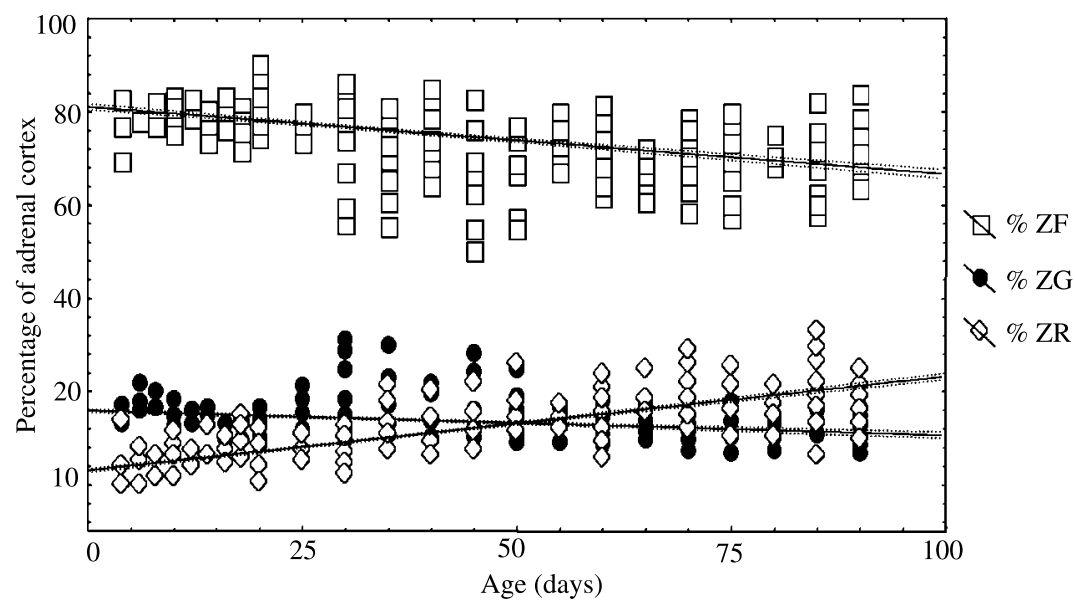

Figure 4 Development of the adrenal cortex - area occupied by each zone. ZF, zona fasciculata; ZG, zona glomerulosa; ZR, zona reticularis. 


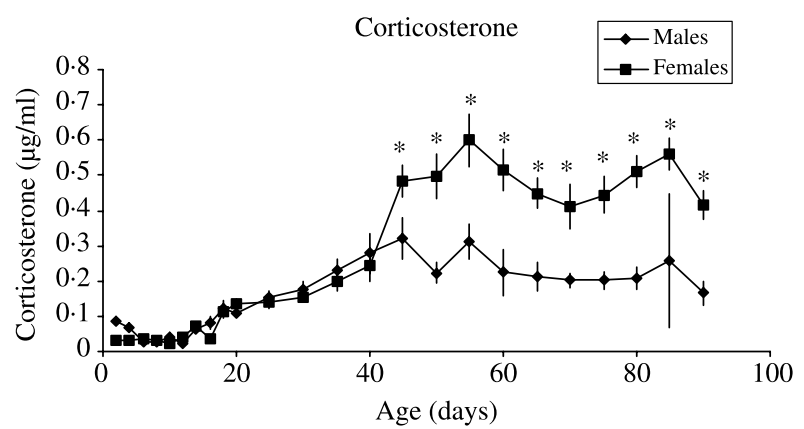

Figure 5 Plasma corticosterone levels during the postnatal period (mean \pm S.E.M., $n \geq 4$ throughout). ${ }^{*} P<0 \cdot 05$.

CYP17. This product was present in developing glands, but hybridization products with a similar melting point in QRT-PCR could not be quantified after 25-60 days of age (CYP17/GAPDH mRNA ratio <0.0001).

\section{Discussion}

We first observed that morphological changes occur in the rat adrenal during the prepubertal period of development. One of these is the increase in adrenal size that at least partly results from the appearance of a new zone, the zona reticularis, which is seen as a clearly identifiable zone only after postnatal day 10, but afterwards it increases in size faster than the other zones (Figs 1-4). Although a specific function of this zone has never been ascertained in the rat, there is a striking resemblance with the development of zona reticularis in humans (Dhom 1973).

We also observed differences in the pattern of secretion of steroid hormones in this period. Corticosterone, the major steroid secreted by the adult rat adrenal, shows maturation of its secretory pattern in the peripubertal period, roughly 45-60 days, during which the characteristic sex dimorphism becomes apparent (Fig. 5). However, other steroids, not normally associated with the adult rat adrenal, were present in the circulating plasma during a period that clearly precedes gonadal maturation. These included androstenedione,

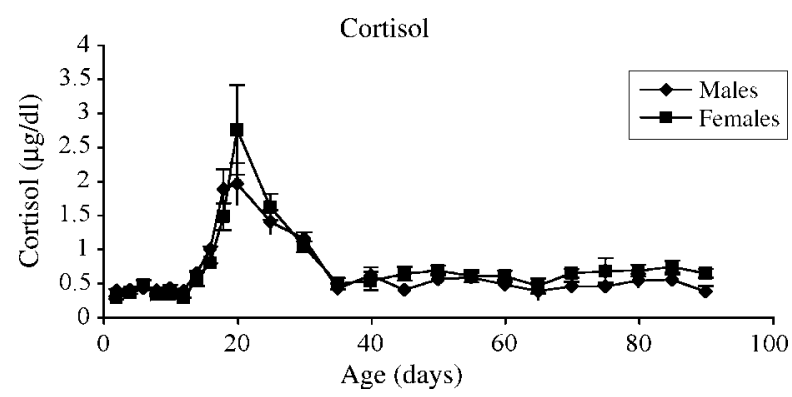

Figure 6 Plasma cortisol levels in male and female rats during the postnatal period (mean \pm S.E.M., $n \geq 6$ throughout). Cortisol was almost undetectable until $14 / 16$ days and again after 35 , with a peak at day 20 .

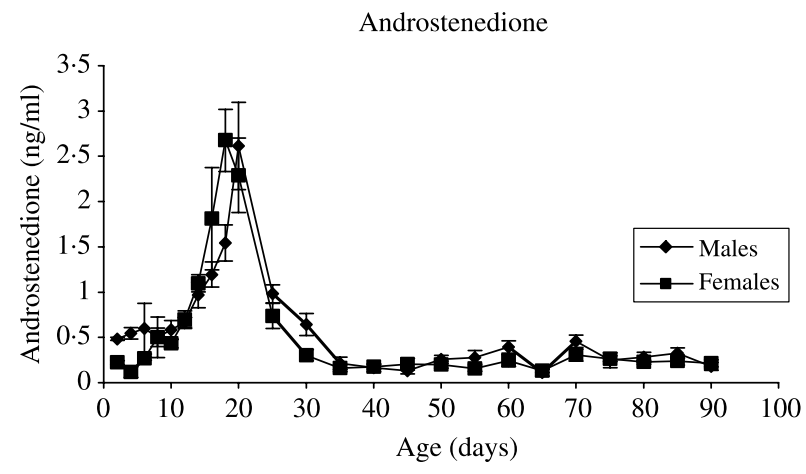

Figure 7 Plasma androstenedione levels in male and female rats during the postnatal period (mean \pm S.E.M., $n \geq 7$ throughout). Androstenedione levels rise until 18-20 days, becoming very low after 35 days, until adulthood.

cortisol, and 17-OH-progesterone (Figs 6-8). All these products depend on CYP17 activity, an enzyme that is generally thought not to exist in the rat adrenal cortex (Fraser 1992, Van Weerden et al. 1992, Katagiri et al. 1998), for their synthesis, except perhaps in the fetus (Keeney et al. 1995). The secretory peaks of cortisol and androstenedione occurred between 16 and 20 days postnatally. The development of circulating testosterone occurred later, reaching its peak at 60 days (Fig. 9), which parallels changes in testis weight (Fig. 10). If this is considered to be an index of the maturation of the testis in males, it is unlikely that testicular CYP17 contributes to the earlier peaks in cortisol and androstenedione (Figs 5 and 6). Indeed, the secretory pattern of 17-OH-progesterone is particularly revealing; it shows two peaks, an early peak at about 20 days, coincident with those of cortisol and androstenedione, and the second in females only at $60+$ days, resembling the rise in testosterone in the male, and perhaps similarly associated with gonadal development.

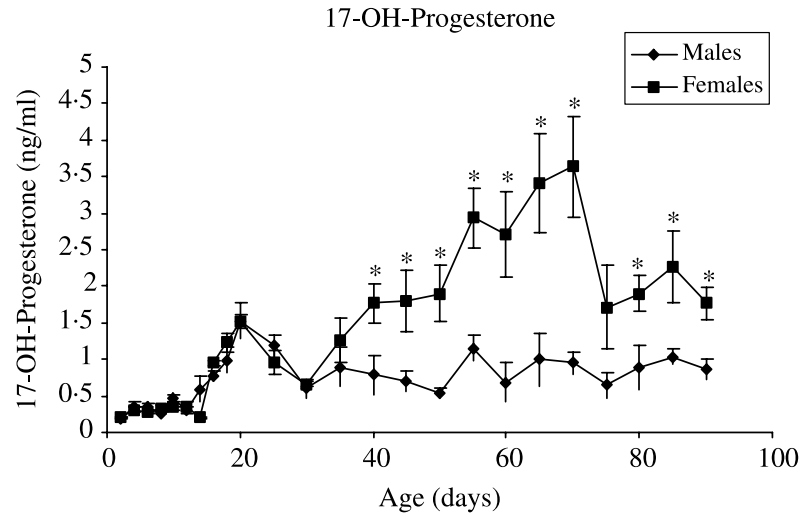

Figure 8 Plasma 17-OH-progesterone levels in male and female rats during the postnatal period (mean \pm s.E.M., $n \geq 7$ throughout). A secretory peak around 20 days is observed. After 35 days, a second peak occurred in females, perhaps through ovarian secretion. ${ }^{*} P<0 \cdot 05$. 


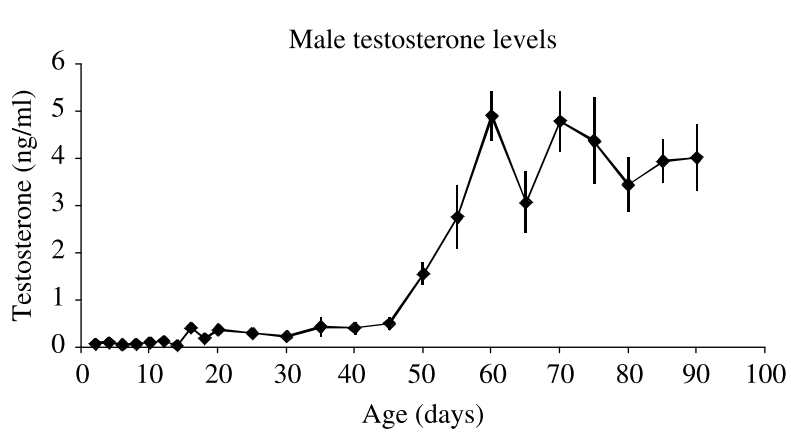

Figure 9 Plasma testosterone levels in male rats during the postnatal period (mean \pm S.E.M., $n \geq 11$ throughout). The first point at which clearly elevated testosterone levels were observed was at day 35 .

It seems likely that the early manifestation of CYP17 activity is attributable to the adrenal. The additional finding of transient transcription of CYP17 in the developing rat adrenal (Fig. 11) is consistent with the circulating steroid data and suggests that at this time, the adrenal may be a significant source of products arising from 17-hydroxylation. A burst of 17-OH-progesterone secretion has already been reported to take place between 10 and 20 days (Tsai \& Johnson 1981) although in that study only females were studied.

The cortisol secretory peak deserves special consideration, since it is a phenomenon that does not occur in the human, where cortisol secretion is stable during the prepubertal and pubertal periods (Pintor et al. 1980). Although cortisol is not a functional glucocorticoid in the adult rodent (Fraser 1992, Katagiri et al. 1998), it has been shown to be the major glucocorticoid in neonatal rabbits and guinea pigs (Hardy et al. 1972, Malinowska et al. 1972).

Despite the reported absence of 17-hydroxylase in the rat adrenal, a number of previous studies have shown that steroid products arising from 17-hydroxylation can be formed from rat adrenal tissue in vitro, including cortisol, androstenedione, and testosterone, among others, albeit at a very low level (Askari 1970, Milewich \& Axelrod 1972, Vinson et al. 1976, 1978a,b, Bell et al. 1979), while in vivo, adrenal production of androgen seems to be evident in the absence of the testis (Bardin \& Peterson 1967, Kniewald et al. 1971).

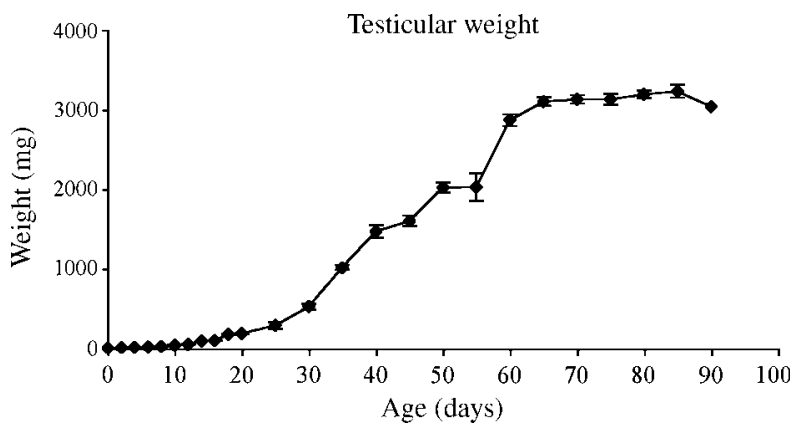

Figure 10 Changes in testicular weight during the postnatal period (mean \pm S.E.M., $n \geq 7$ throughout).
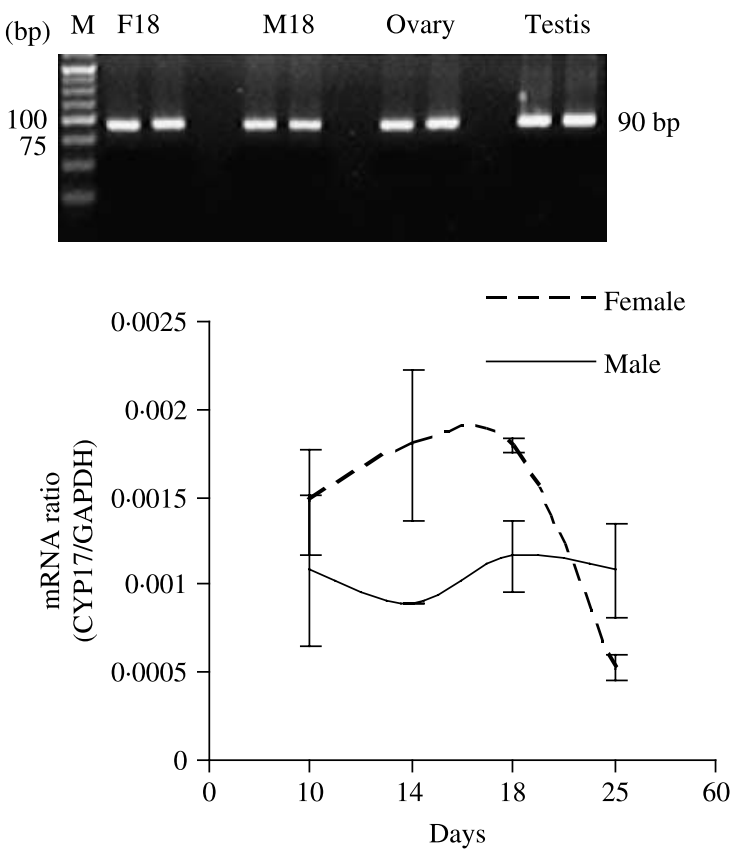

Figure $11 \mathrm{PCR}$ of mRNA obtained from developing rat adrenals. Both female and male glands at 18 days (F18 and M18) gave PCR products of a size (90 base pairs, bp, cf. $M$, marker) expected for CYP17 and identical to those obtained with mRNA from ovary and testis. Quantitative RT-PCR (lower figure) showed that these products were present in the developmental period, but could not be quantified (Cyp17/GAPDH mRNA ratio <0.0001) after 25-

60 days of age (mean \pm s.E.M., $n=4)$.

However, it remains possible that circulating cortisol or androgens could arise from the interaction between different organs and that the adrenal could merely provide precursors for CYP17 action at other sites, and an adrenal-testis interaction has been proposed (Feek et al. 1985, 1989). The testis is not the only possible site for conversion of adrenal products and in this connection it is important to note that the presence of 17-hydroxylase has also been demonstrated in rat hepatic cells, again between postnatal days 14 and 21 (Vianello et al. 1997, Katagiri et al. 1998). The possibility of such 'cooperation' between the liver and other tissues has been suggested in other situations, for example, in humans where the liver collaborates with the fetal adrenal and the placenta to produce oestriol (Bolander 1989) and with the skin and the kidney for the production of $1 \alpha, 25$-dihydroxycholecalciferol (Bolander 1989).

Taken together, the morphological changes, the hormone assay data, and the presence of mRNA coding for CYP17 more strongly suggest that a true adrenarche is taking place in these rodents. The steroids produced at such a specific time of the rat prepubertal period may have a role in prepubertal development. In the human, this idea has been the subject of some dispute since precocious adrenarche may not always be followed by similarly precocoius puberty (Sizonenko \& Paunier 1975, Lee \& Gareis 1976), and precocious puberty 
may occur without prior adrenarche. (Sizonenko \& Paunier 1975, Sklar et al. 1980, Counts et al. 1987). In the first case, it may be that steroids produced in the adrenal only produce their effects on prepared or primed gonads or hypothalamus; the second case suggests an independent pathology. In the normal situation, one possibility would be that androgens originating in the liver and adrenal gland are substrates for CYP18-mediated oestrogen synthesis by Sertoli or granulosa cells and hence help to support the proliferation of those cells (Vianello et al. 1997) in a period at which the gonads do not produce enough androgen substrate on their own.

However, cortisol cannot be converted into oestrogens. Thus, an alternative interpretation might be that this is a purely adrenal event, perhaps in response to a significant stress that might occur in this period. Curiously, it is precisely during this period that separation from the mother takes place. The specific functions of cortisol that are not shared by corticosterone are not clear. What is clear is that this is a real phenomenon, and its significance needs to be addressed.

\section{Acknowledgements}

The authors declare that there is no conflict of interest that would prejudice the impartiality of this scientific work.

\section{References}

Albright F, Smith P \& Fraser R 1942 A syndrome characterized by primary ovarian insufficiency and decreased stature: report of 11 cases with a digression on hormonal control of axillary and pubic hair. American Journal of Medical Science 204 625-648.

Andò S, Canonaco M, Beraldi E, Valenti A, Maggiolini M, Piro A, Tavolaro R \& De Fulgheri F 1988 The evaluation of androgen circulating levels following castration in adult male rats. Experimental and Clinical Endocrinology 91 311-318.

Andò S, Canonaco M, Valenti A, Aguila S, Tavolaro R, Panno M \& DessiFulgheri $\mathrm{F} 1989$ The in vitro conversion of $3 \mathrm{H}$-androstenedione to testosterone and dihydrotestosterone in the adrenal gland of castrated male rat: influence of gonadal steroid administration. Experimental and Clinical Endocrinology 93 83-89.

Askari HA 1970 Sexual differences in the biogenesis of the androgens by the adrenal cortex in rat. Endocrinology 87 1377-1380.

Bardin CW \& Peterson RE 1967 Studies of androgen production by the rat: testoterone and androstenedione content of blood. Endocrinology $8038-44$.

Bell JB, Gould RP, Hyatt PJ, Tait JF \& Tait SA 1978 Properties of rat adrenal zona reticularis cells: preparation by gravitational sedimentation. Journal of Endocrinology 77 25-41.

Bell JB, Gould RP, Hyatt PJ, Tait JF \& Tait SA 1979 Properties of rat adrenal zona reticularis cells: production and stimulation of certain steroids. Journal of Endocrinology 83 435-447.

Belanger B, Couture J, Caron S, Bodou P, Fiet J \& Belanger A 1990 Production and secretion of C-19 steroids by rat and guinea pig adrenals. Steroids $\mathbf{5 5}$ 335-360.

Bolander F 1989 Molecular Endocrinology, pp 16-48. San Diego (USA): Academic Press.

Boyar R, Finkelstein J, David R, Roffwarg H, Kapen S, Weitzman E \& Hellman L 1973 Twenty-four hour patterns of plasma LH and FSH in sexual precocity. New England Journal of Medicine 289 282-286.

Corey E \& Britton S 1931 The induction of precocious sexual maturity by corticoadrenal extract. American Journal of Physiology 99 33-43.
Counts D, Pescovitz O, Barnes K, Hench K, Chrousos G, Sherins R, Comite F, Loriaux D \& Cutler G 1987 Dissociation of adrenarche and gonadarche in precocious puberty and in isolated hypogonadotropic hypogonadism. Journal of Clinical Endocrinology and Metabolism 64 1174-1178.

Cutler G \& Loriaux L 1980 Adrenarche and its relationship to the onset of puberty. Federation Proceedings 39 2384-2390.

Cutler G, Glenn M, Bush M, Hodgen G, Graham C \& Loriaux L 1978 Adrenarche: a survey of rodents, domestic animals and primates. Endocrinology 103 2112-2118.

Dhom G 1973 The prepubertal and pubertal growth of the adrenal (adrenarche). Beiträge zur Pathologie 150 357-377.

Ducharme J, Forest M, de Peretti E, Sempe M, Collu R \& Bertrans J 1976 Plasma adrenal and gonadal sex steroids in human pubertal development. Journal of Clinical Endocrinology and Metabolism 42 468-476.

Feek CM, Tuzi NL, Williams BC, Burt D, Wu FC, Wallace AM, Gray CE \& Edwards CR 1985 The adrenal secretion of progesterone stimulates testicular steroidogenesis in the rat in vitro. Journal of Steroid Biochemistry and Molecular Biology 23 617-623.

Feek CM, Tuzi NL \& Edwards CR 1989 The adrenal gland and progesterone stimulates testicular steroidogenesis in the rat in vivo. Journal of Steroid Biochemistry and Molecular Biology 32 573-579.

Forest M, Saez J \& Bertrand J 1975 Present concept of initiation of puberty, neonatal and prepubertal hormonal influences. In Some Aspects of Hypothalamic Regulation of Endocrine Functions, pp 339-378.

Ed. P Franchimont. Stuttgart: Schattauer.

Fraser R 1992 Biosynthesis of adrenocortical steroids. In The Adrenal Gland, pp 117-130. Ed. VHT James. New York: Raven Press.

Genazzani A, Pintor C, Facchinetti F, Carboni G, Pelosi U \& Corda R 1978 Adrenal and gonadal steroids in girls during sexual maturation. Clinical Endocrinology 8 15-25.

Gorsky M \& Lawton I 1973 Adrenal involvement in determining the time of onset of puberty in the rat. Endocrinology 93 1232-1234.

Grumbach M, Richards G, Conte F \& Kaplan S 1978 Clinical disorders of the adrenal function and puberty: an assessment of the role of the adrenal cortex in normal and abnormal puberty in man and evidence for an ACTH-like pituitary adrenal androgen stimulating hormone. In The Endocrine Function of the Human Adrenal Cortex, pp 583-612. Eds VHT James, M Serio, G Giusti \& L Martini. New York: Academic Press.

Hardy R, Malinowska K \& Nathanielsz P 1972 Plasma adrenocortical steroids immediately after birth in the rat, rabbit and guinea pig. Journal of Endocrinology 55. XXXIV.

Hopper B \& Yen S 1975 Circulating concentrations of DHA and DHAS during puberty. Journal of Clinical Endocrinology and Metabolism 40 458-461.

Horikoshi T \& Sakakibara M 2000 Quantification of relative mRNA expression in the rat brain using simple RT-PCR and ethidium bromide staining. Journal of Neuroscience Methods. 99 45-51.

Houssay B, Houssay A \& Cardega A 1953 Adrenal tumors in gonadectomized rats. Acta Physiologica Latinoamerica 3 125-130.

Katagiri M, Tatsuta K, Imaoka S, Funae Y, Honma K, Matsuo N, Yokoi H, Ishimura K, Ishibashi F \& Kagawa N 1998 Evidence that immature rat liver is capable of participating in steroidogenesis by expressing $17 \alpha-$ hydroxylase/17,20-lyase P450c17. Journal of Steroid Biochemistry and Molecular Biology 64 121-128.

Katz S, Hediger M, Zemel B \& Parks J 1985 Adrenal androgens, body fat and advanced skeletal age in puberty: new evidence for the relations of adrenarche and gonadarche in males. Human Biology 57 401-413.

Keeney D, Jenkins C \& Waterman M 1995 Developmentally regulated expression of adrenal $17 \alpha$-hydroxylase cytochrome P450 in the mouse embryo. Endocrinology 136 4872-4879.

Kniewald Z, Zanisi M \& Martini L 1971 Studies on the biosynthesis of testosterone in the rat. Acta Endocrinologica 68 614-624.

Korth-Schutz S, Levine L \& New M 1976 Serum androgens in normal prepubertal and pubertal children with precocious adrenarche. Journal of Clinical Endocrinology and Metabolism 42 117-124.

Leal AM \& Moreira AC 1997 Daily variation of plasma testosterone, androstenedione, and corticosterone in rats under food restriction. Hormones and Behaviour 31 97-100. 
Lee P \& Gareis FJ 1976 Gonadotropin and sex steroid response to LHRH in patients with premature adrenarche. Journal of Clinical Endocrinology and Metabolism 43 195-197.

Lee P \& Migeon C 1975 Puberty in boys: correlation of plasma levels of gonadotropins (LH and FSH), androgens (testosterone, androstenedione, DHA and DHAS), estogens (estrone and estradiol) and progestins (progesterone and 17-OH-progesterone). Journal of Clinical Endocrinology and Metabolism 41 556-562.

Malinowska K, Hardy R \& Nathanielsz P 1972 Plasma adrenocorticosteroid concentrations immediately after birth in the rabbit and guinea pig. Experientia 28 1366-1367.

Milewich L \& Axelrod LR 1972 The conversion in vitro of pregnenolone to C19 and C21 metabolites by the rat adrenal gland, with and without metyrapone. Journal of Endocrinology 54 515-516.

Moon H 1937 Effect of ACTH on the sexual development of spayed rats. Proceedings of the Society of Experimental Biology and Medicine 3736.

Ojeda S, Andrews W, Advis J \& White S 1980 Recent advances in the endocrinology of puberty. Endocrine Reviews $1228-257$.

Parker L 1991 Adrenarche. Endocrine Clinics of North America 20 71-83.

Parker L \& Odell W 1980 Control of adrenal androgen secretion. Endocrine Reviews 1 392-410.

Parker L, Sack J, Fisher D \& Odell W 1978 The adrenarche: prolactin, gonadotropins, adrenal androgens and cortisol. Journal of Clinical Endocrinology and Metabolism 46 396-401.

Pelletier G, Li S, Luu-The V, Tremblay Y, Belanger A \& Labrie F 2001 Immunoelectron microscopic localization of three key steroidogenic enzymes (cytochrome P450(scc), 3 beta-hydroxysteroid dehydrogenase and cytochrome $\mathrm{P} 450(\mathrm{c} 17)$ in rat adrenal cortex and gonads. Journal of Endocrinology 171 373-383.

de Peretti E \& Forest M 1976 Unconjugated DHA: plasma levels in normal subjects from birth to adolescence in human: the use of a sensitive radioimmunoassay. Journal of Clinical Endocrinology and Metabolism 43 982-991.

Perez-Fernandez R, Facchinetti F, Beiras A, Lima L, Gaudiero G, Genazzani A \& Devesa J 1987 Morphological and functional stimulation of adrenal reticularis zone by dopaminergic blockade in dogs. Journal of Steroid Biochemistry and Molecular Biology 28 465-470.

Pintor C, Genazzani A, Carboni G, Fanni T, Orani S, Facchinetti F \& Corda R 1980 Adrenal androgens and pubertal development in physiological and pathological conditions. In Adrenal Androgens, pp 173 181. Eds A Genazzani, H Thijssen \& P Siiteri. New York: Raven Press.

Reiter E, Fuldauer V \& Root A 1977 Secretion of the adrenal androgen, DHAS, during normal infancy, childhood and adolescence in sick infants and in children with endocrinological abnormalities. Journal of Pediatrics 90 766-770.

Rich B, Rosenfield R, Lucky A, Helke J \& Otto P 1981 Adrenarche: changing adrenal response to ACTH. Journal of Clinical Endocrinology and Metabolism 52 1129-1136.

Rilianawati, Paukku T, Kero J, Zhang F, Rahman N, Kananen K \& Huhtaniemi I 1998 Direct luteinizing hormone action triggers adrenocortical tumorigenesis in castrated mice transgenic for the murine inhibinalpha subunit promoter/simian virus 40 T-antigen fusion gene. Molecular Endocrinology 12 801-809.

Rilianawati, Kero J, Paukku T \& Huhtaniemi I 2000 Long-term testosterone treatment prevents gonadal and adrenal tumorigenesis of mice transgenic for the mouse inhibin-alpha subunit promoter/simian virus $40 \mathrm{~T}$-antigen fusion gene. Journal of Endocrinology 166 77-85.

Rosenfield R \& Eberlein W 1969 Plasma 17-ketosteroid levels during adolescence. Journal of Pediatrics 74 932-936.
Sizonenko P 1978 a Endocrinology in pre-adolescents and adolescents. I. Hormonal changes during normal puberty. American Journal of the Diseases of Childhood 132 704-712.

Sizonenko P 1978 b Pre-adolescent and adolescent endocrinology: physiology and physio-pathology. II. Hormonal changes during abnormal pubertal development. American Journal of the Diseases of Childhood 132 797-805.

Sizonenko P \& Paunier L 1975 Hormonal changes in puberty III. Correlation of plasma DHA, testosterone, FSH and LH with stages of puberty and bone age in normal boys and girls and in patients with Addison's disease or hypogonadism or with premature or late adrenarche. Journal of Clinical Endocrinology and Metabolism 41 894-904.

Sklar C, Kaplan S \& Grumbach M 1980 Evidence for dissociation between adrenarche and gonadarche: studies in patients with idiopathic precocious puberty, gonadal dysgenesis, isolated gonadotropin deficiency and constitutionally delayed growth and adolescence. Journal of Clinical Endocrinology and Metabolism 51 548-556.

Smail P, Faiman C, Hobson W, Fuller G \& Winter J 1982 Further studies on adrenarche in nonhuman primates. Endocrinology 111 844-848.

Thompson CJ, Ross SM, Hensley J, Liu K, Heinze SC, Young SS \& Gaido KW 2005 Differential steroidogenic gene expression in the fetal adrenal gland versus the testis and rapid and dynamic response of the fetal testis to di(n-butyl) phthalate. Biology of Reproduction 73 908-917.

Tsai C \& Johnson D 1981 Production of 17-hydroxypregnenolone and 17-hydroxyprogesterone by the immature rat ovary. Steroids 37 627-634.

Van Weerden W, Bierings H, Steenbrugge G, Jong F \& Schroder F 1992 Adrenal glands of mouse and rat do not synthesize androgens. Life Sciences 50 857-861.

Vianello S, Waterman M, Dalla Valle L \& Colombo L 1997 Developmentally regulated expression and activity of $17 \alpha$-hydroxylase/C-17,20-lyase cytochrome P450 in rat liver. Endocrinology 138 3166-3174.

Vinson GP, Bell JBG \& Whitehouse BJ 1976 Production of testosterone and corticosteroids by rat adrenal-gland incubated in vitro and effects of stimulation with ACTH, LH and FSH. Journal of Steroid Biochemistry and Molecular Biology 7 407-411.

Vinson GP, Whitehouse BJ \& Goddard C $1978 a$ Effect of sex and strain of rats on in vitro response of adrenocortical tissue to ACTH stimulation. Journal of Steroid Biochemistry and Molecular Biology 9 553-560.

Vinson GP, Whitehouse BJ \& Goddard C $1978 b$ Steroid 17-hydroxylation and androgen production by incubated rat adrenal tissue. Journal of Steroid Biochemistry and Molecular Biology 9 677-683.

Winter J, Faiman C, Hobson W \& Reyes F 1980 The endocrine basis of sexual development in the chimpanzee. Journal of Reproduction and Fertility 28 131-138.

Woolly G 1953 Evidence that adrenal corticoid tumors in aged gonadectomized hamsters produce sex-like hormones. Anatomical Record 115381.

Woolly G, Fekete E \& Little C 1939 Mammary tumor development in mice ovariectomized at birth. PNAS 25 277-279.

Xiao F, Puddefoot JR, Barker S \& Vinson GP 2004 Mechanism for aldosterone potentiation of angiotensin II-stimulated rat arterial smooth muscle cell proliferation. Hypertension 44 340-345.

Received 22 May 2006

Accepted 13 July 2006 